\title{
BROCA'S AREA AND INFLECTIONAL MORPHOLOGY: EVIDENCE FROM BROCA'S APHASIA AND COMPUTER MODELING
}

\author{
Martina Penke ${ }^{1}$ and Gert Westermann ${ }^{2}$ \\ ( ${ }^{1}$ Department of General Linguistics, Institut of Language and Information, Heinrich-Heine University Düsseldorf, \\ Düsseldorf, Germany; ${ }^{2}$ Department of Psychology, Oxford Brookes University, Oxford, UK)
}

\begin{abstract}
In a series of articles Ullman (2001, 2004; Ullman et al., 1997) has proposed that regular inflection is critically subserved by Broca's area. This suggestion is motivated by the finding that English speaking Broca's aphasics show selective deficits with regular inflection. Here we argue that this proposal does not hold cross-linguistically but is based on a confound between inflectional suffix and regularity that is specific to the English language. We present data from two experimental studies of participle inflection with 13 German and 12 Dutch Broca's aphasics. None of these aphasic speakers are selectively impaired for regular inflection but instead most of them show selective deficits with irregular inflection. These data suggest that a selective regular deficit is not a characteristic of Broca's aphasia across languages, and that Broca's area is not critically involved in regular inflection. To investigate the nature and localization of the processes underlying inflection we present a connectionist neural network model that accounts for the deficits of the German aphasic speakers. The model implements the view that the inflection of all verb types is based on a single mechanism with multiple representations that emerge from experience-dependent brain development. We show that global damage to this model results in a selective deficit for irregular inflection that is comparable to that of the German aphasic speakers. This finding suggests that a selective impairment of irregular participles as observed by German and Dutch aphasic speakers does not presuppose two distinctly localized mechanisms or processes that can be selectively affected by brain damage.
\end{abstract}

Key words: Broca's area, Broca's aphasia, verb inflection, connectionist modelling

\section{INTRODUCTION}

In many languages and inflectional systems regular and irregular inflected forms exist side by side. Consider for instance English past-tense formation, where we find regular forms inflected with -ed (laugh - laughed) and irregular ones like went that are idiosyncratic and largely unpredictable. According to an influential view in linguistics and psycholinguistics - most prominently defended by Pinker (1999) - regular inflected forms are generated by the application of a symbolic mental rule (add -ed), whereas irregular forms are stored in the mental lexicon. The distinction between irregular and regular forms has been argued to exemplify the distinction between a mental lexicon, where words are stored together with learned idiosyncratic information, and a mental grammar component that contains the rules to generate composite structures such as sentences and complex words out of the stored elements in the mental lexicon (Pinker, 1999; Clahsen, 1999; Ullman, 2001; Pinker and Ullman, 2002).

In a series of papers, Ullman (2001, 2004; Ullman et al., 1997) has aimed to localize regular and irregular inflectional components in the brain. Results from past-tense inflection tasks in Englishspeaking Broca's aphasics have been a central aspect of his proposal that regular inflection is subserved by Broca's area (Ullman, 2001, 2004; Ullman et al., 1997) ${ }^{1}$. In a production task where regular and irregular past-tense forms were elicited, Ullman et al. (1997) found a marked deficit in the production of regular past-tense forms in an English-speaking subject with agrammatic Broca's aphasia. This patient, FCL, had suffered a stroke that resulted in a left frontal brain lesion encompassing Broca's area. Whereas FCL produced correct irregular past-tense forms for $69 \%$ of the presented present-tense forms, only $20 \%$ of the regular past-tense forms were produced correctly. Moreover, the regular past-tense affix -ed was neither over-applied to irregular verbs, nor was it used to produce past-tense forms for pseudoverbs as typically observed in unimpaired control subjects. The opposite profile was observed for a second aphasic speaker, JLU, whose language impairment was classified as fluent anomic aphasia. JLU had suffered a lesion in the left temporo-parietal cortex, but Broca's area was completely spared. In contrast to FCL, subject JLU displayed a far better performance for regular pasttense forms (85\% correct) than for irregular ones $(63 \%$ correct). In addition, he used the regular

\footnotetext{
${ }^{1}$ According to Ullman's $(2001,2004)$ declarative/procedural model of grammar other brain structures, mainly the basal ganglia, are also implied in the learning and processing of grammatical rules. Broca's area, however plays an "especially important role" (Ullman, 2004, p. 246) in this system of frontal/basal ganglia circuits, and Ullman (2001) explicitly links the computation of regular inflected forms to left anterior brain regions especially Broca's area.
} 
suffix -ed to productively build past-tense forms for pseudo-verbs - just as the unimpaired controls did. The observed dissociation between these two subjects was supported by results from two larger groups of subjects with less circumscribed lesions. Subject FCL and four other agrammatic subjects with extended lesions encompassing Broca's area displayed a selective deficit in reading regular inflected past-tense forms (mean correctness scores: $20 \%$ for regulars, $52 \%$ for irregulars). A group of five anomic aphasics with lesions encompassing temporal and/or parietal brain regions, in contrast, performed significantly better in the production of regular past-tense forms (mean correctness score $83 \%$ ) compared to the production of irregular pasttense forms (71\% correct). Ullman (2001, 2004) interpreted these results as core evidence for his claim that regular inflection is subserved by Broca's area whereas irregular inflected forms are stored in temporal and parietal cortical regions. Since Broca's aphasia is generally associated with lesions encompassing Broca's area (Alexander, 1997; Alexander et al., 1990; Damasio, 1992; Dronkers et al., 2000), Ullman (2004) proposed that an impairment of regular inflection is a characteristic sign of agrammatic Broca's aphasia.

Ullman's claim that impairments with regular inflection are connected to left frontal brain lesions is confirmed by results from auditory priming experiments conducted with Englishspeaking aphasic subjects (Marslen-Wilson and Tyler, 1997, 1998; Tyler et al., 2002). For unimpaired listeners lexical-decision times for verbs such as jump or give are speeded up (priming effect) when they are preceded by their respective past-tense forms jumped or gave. Five agrammatic subjects, who had suffered lesions encompassing left frontal brain areas, displayed this priming effect with irregular past-tense forms (gave - give), but contrary to the control subjects, a priming effect did not occur after presentation of regular past-tense forms (jumped - jump). Marslen-Wilson and Tyler (1998) conclude that this finding provides evidence "for the role of posterior frontal brain regions in the processing of the regular past tense" (p. 432).

Other researchers have however doubted that a selective deficit with regular past-tense inflection is a characteristic sign in English Broca's aphasia. In a detailed experimental investigation Bird et al. (2003) showed that a selective deficit for the production of regular past-tense forms apparent in ten subjects with Broca's aphasia disappeared when the tested verbs were controlled for phonological complexity. A similar deficit in the production of both regular and irregular past-tense forms was also found in a multiple-choice sentence completion task conducted with seven agrammatic Broca's aphasic subjects (Faroqi-Shah and Thompson, 2003).

Note, however, that almost all of the agrammatic subjects tested in these studies displayed severe problems with the production of regular past-tense forms. Bird et al. (2003) report a mean correctness score for regular participles of only $29 \%$ in the phonologically controlled material. The respective score in Faroqi-Shah and Thompson's (2003) study is 50\%. Moreover, an analysis of the errors produced by the aphasic subjects in Bird et al.'s (2003) study revealed that most of the incorrect forms were produced as the stem of the presented verb or as forms with little resemblance to the target. Overapplications of the regular past-tense ending to irregular verbs were not reported. Thus, whereas a selective deficit of regular past-tense forms compared to irregular ones could not be found in these two studies, these studies have nevertheless provided evidence that regular inflection is impaired in speakers with Broca's aphasia. Therefore these findings do not rule out the possibility that damage to Broca's area in subjects with Broca's aphasia leads to a deficit with regular inflection due to an impairment of the rule component of the language system. The impairment of irregular past-tense forms reported in these studies might then be due to damage to some other neural/cognitive system also affected in these subjects.

The investigation of the English past tense is, however, not ideally suited to investigate Ullman's claim since in English regularity and irregularity are confounded with the presence or absence of inflectional affixes. Whereas regular past-tense forms are formed by affixation of the suffix -ed, irregular past-tense forms often only display a change of the stem vowel (e.g., sing $\rightarrow$ sang). Therefore, a deficit affecting only regular inflection cannot be distinguished from a deficit affecting inflectional endings in general, since the only inflectional endings are regular affixes.

A number of cross-linguistic studies on the production of inflected elements in Broca's aphasia have found that omissions of functional elements are frequent in English-speaking individuals with Broca's aphasia, whereas omission rates are markedly lower in languages such as Finnish, German, Italian, Polish or Spanish where inflectional systems are more elaborate and express more syntactic information (Bates et al., 1987, 1991b; Benedet et al., 1998; Kehayia et al., 1990; Menn and Obler, 1990; Niemi et al., 1990). To explain this finding, Bates et al. (1987, 1991b) proposed that the number of inflectional elements omitted by aphasic speakers is related to the amount of syntactically relevant information expressed by these elements: the less important the information expressed by inflectional markers, the more often they are omitted. Bates et al. (1987, 1991b) hypothesized that in experiencing a limitation of their sentenceprocessing capacities individuals with Broca's aphasia neglect those elements that are of minor importance in the language system. English is an analytic language with a largely reduced inflectional component. Hence inflectional markers, which are 
of minor syntactic importance in English, are often omitted in English Broca's aphasia ${ }^{2}$. Due to a peculiarity of English inflectional systems, the omission of inflectional endings can only affect regular inflected forms, since it is only these forms that have inflectional endings. Consequently, an impairment leading to a reduction of processing capacities as suggested by Bates et al. $(1987,1991 b)$ would resemble a selective deficit of regular inflection in English Broca's aphasia. Whether or not this suggestion is valid, it cautions us against the effects that different grammatical systems might exert on the manifestation of language impairments in a specific language. Cross-linguistic evidence is needed to determine whether deficits found in one language can be considered to be a general characteristic of a specific language disorder such as Broca's aphasia.

In this paper we present evidence that, contrary to Ullman's claim, a deficit with regular inflection is not a characteristic sign of Broca's aphasia across languages, and that consequently regular inflection is not dependent on Broca's area. We report results from two studies on regular and irregular past-participle inflection that were conducted with 13 German- and 12 Dutch-speaking subjects with Broca's aphasia. The system of pastparticiple inflection in these languages is very similar to the English past tense in that both languages, like English, distinguish between regular and irregular inflected forms. In contrast to English, however, both regular and irregular participles have endings that are separable from the verb stem. The investigation of inflectional deficits in these two languages thus allows us to disentangle the confound between regularity and separable ending that is present in English.

We will further investigate the possibility of a global deficit as the cause for differential impairments of regular and irregular forms with a neural network model of verb inflections in German Broca's aphasic speakers. In Ullman's declarative/procedural model selective deficits with regular or irregular forms result from damage to distinct neural processing systems: damage of the frontal/basal ganglia circuits leads to a deficit with regular inflection, whereas lesions to temporoparietal brain areas are responsible for impairments with irregular inflected forms. Similarly, a previous single-mechanism connectionist model has been used to suggest that selective deficits for regular forms arise from damage to a phonological component, whereas irregular deficits are a consequence of a damaged semantic system (Joanisse and Seidenberg, 1999). Contrary to these positions, in this paper we show that selective deficits with irregular forms can

${ }^{2}$ In fact, Bates et al. (1987, 1991b) found that even unimpaired speakers of English tend to ignore information provided by inflectional elements in sentence processing, thereby supporting their view that inflectional markers in English are of little relevance in the language system (MacWhinney and Bates, 1989; MacWhinney et al., 1984). arise from a global deficit in a single mechanism system that does not rely on separate phonological and semantic components.

The rest of this paper is organized as follows: the next Section gives a short overview of past-participle inflection in German and Dutch. We then report our experimental results and present a simulation of the German aphasics' data in a neural network model. This simulation suggests that the deficits observed in the German aphasic speakers can be accounted for by damage that does not disrupt specific pathways or mechanisms for regular and irregular forms but that globally affects the whole system. The paper concludes with a discussion of the implications of our results for Ullman's proposal on the role of Broca's area in regular inflection.

\section{Past Participle Formation in German AND Dutch}

German past participles are formed with a phonologically conditioned prefix ge-, a verb-stem and the endings $-t$ or $-n$. Regular inflected verbs do not show stem changes in the participle and are suffixed with - $t$ (1a-b). In contrast, irregular inflected verbs often show a modification of the stem vowel in the participle stem and take the participle ending -en (1c). Neither the stem-vowel nor the phonological shape of the stem predict whether a verb is regular or irregular. Consider for example the verbs blinken 'flash' and trinken 'drink': whereas trinken (1c) has the irregular participle form getrunken, the verb blinken (1b) has the regular participle form geblinkt.

\begin{tabular}{llll} 
& Infinitive & Participle & Gloss \\
\hline (1a) tanz-en & ge-tanz-t & 'dance' \\
(1b) blink-en & ge-blink-t & 'flash' \\
(1c) trink-en & ge-trunk-en & 'drink'
\end{tabular}

According to the dualistic approach to inflection most notably advocated by Pinker (1999), two qualitatively different cognitive mechanisms are responsible for the inflection of regular and irregular participles: whereas regular participles such as getanzt 'danced' (1a) are generated on the fly by combining the basic verb stem tanz- with the participle affix - $t$, irregular participles such as getrunken 'drunk' (1c) are stored with information about the stem change and the -en ending (e.g. Wunderlich, 1996).

The Dutch system of past-participle inflection is very similar to the German one. As in German, Dutch past participles consist of a prefix $g e-$, a verb stem and one of the endings $-t /-d$ or $-e n$. Regular participles such as geopend 'opened' or geblaft 'barked' are formed with the basic verb stem (open-, blaf-) that is suffixed with $-t /-d^{3}$.

${ }^{3}$ The distribution of the orthographical endings $-t$ or $-d$ is dependent on the last consonant of the verb stem. Both endings are pronounced as $[t]$. 
Irregular participles such as gevonden 'found' are formed with a participle stem that often shows a change in the stem vowel (e.g., vind- - gevonden), and take the ending -en.

Whereas English, German, and Dutch are very similar in that they all distinguish between regular and irregular inflected verbs and mark pastness by stem changes in irregular verbs and by an alveolar plosive $(-t,-d)$ in regular verbs, they differ in that German and Dutch - in contrast to English - have a segmentable ending (-en) for irregular participles.

\section{Participle Production in German and Dutch BROCA's APHASIA}

In this section we provide evidence that regular participle inflection is not selectively impaired in German and Dutch Broca's aphasia. We report results from two production experiments conducted to elicit regular and irregular past-participle forms. The procedure adopted in these two experiments was largely identical to the procedure chosen by Ullman et al. (1997).

\section{Regular and Irregular Participles in German Broca's Aphasia}

The main results on German Broca's aphasia come from an experimental study published in Penke et al. (1999). In this study participle forms for 39 regular verbs, 39 irregular verbs and five non-rhyming pseudo-verbs were elicited from 11 German individuals with agrammatic Broca's aphasia. In the experiment, subjects had to complete a sentence by transforming a given first person singular present tense form that was introduced in a short sentence (e.g., Ich schreibe. 'I am writing') into a past participle (Ich habe __? [geschrieben]. 'I have written'). Since the publication of these data we have been able to analyze data from two additional aphasic subjects tested with the same material. Here, we present a summary of the published results enriched by the data from these two additional subjects. All 13 subjects had been classified as Broca's aphasics by the standard Aachen Aphasia test-battery (Huber et al., 1983). Subjects were right-handed native speakers without language problems prior to aphasia who had suffered a left hemispheric insult at least three years before our investigation (see Table I for more information on the subjects; for details concerning the experimental procedure see Penke et al., 1999).

A comparison of the correctness scores for regular and irregular participles reveals that regular inflection was largely spared in the 13 agrammatic subjects (see Figure 1). On average, only $8.8 \%$ of the regular inflected participles were not produced correctly. In contrast, with an average of $33 \%$, error rates for irregular participles were significantly higher $[t(12)=4.057, p=.002]$. As can be seen from the individual data in Figure 1, none of the agrammatic subjects displayed a selective deficit for regular participles. However, 10 of the 13 aphasic subjects had selective problems with the inflection of irregular forms. Only three of the 13 subjects displayed comparable problems for regular and irregular participle formation (subjects GB to FW) - but even in these cases there is no evidence for a selective deficit affecting only regular inflection.

In addition, all aphasic subjects frequently overapplied the regular participle affix $-t$ to produce participle forms for irregular verbs (i.e. getrinkt instead of the correct getrunken). In total $81 \%$ of the 152 errors that occurred for irregular participles were such over-regularizations with the regular participle affix - $t$. Moreover, subjects productively applied the regular affix - $t$ to form participles for pseudo-verbs: $66 \%$ of the pseudo-verbs (that were dissimilar to any existing German verbs) were suffixed with $-t$, but only $7 \%$ with $-n$. These findings indicate that all aphasic subjects were able to make productive use of the regular affix $-t$ in participle formation.

Our findings on German Broca's aphasia are in marked contrast to the results reported for Englishspeaking subjects with Broca's aphasia who displayed severe impairments in producing regular inflected past-tense forms and only rarely applied the regular ending to irregular verbs or pseudoverbs (Ullman et al., 1997; Bird et al., 2003; Faroqi-Shah and Thompson, 2003, 2004). By contrast, the data of our German aphasic subjects indicate that in German Broca's aphasia it is irregular but not regular inflection that is selectively impaired ${ }^{4}$.

A frequency analysis of the errors revealed that errors with irregular participles, but not with regular participles, were dependent on the frequency of occurrence of the respective participle form. The experimental material included both frequent participles (participle frequency of each verb $>100$ in the 6-million-token CELEX (Communitatis Europeae Lex) database (Baayen et al., 1993) and very infrequent participles (participle frequency of each verb $<10$ according to CELEX $)^{5}$. A comparison of the error rates for these infrequent and frequent participles yielded a significant frequency effect for irregular participles: whereas the mean error rate for infrequent participles was $43.7 \%$ it dropped to $16.7 \%$ for frequent participles $[t(12)=3.643, p=.003]$. Error rates for regular participles, in contrast, were not

\footnotetext{
${ }^{4}$ For a similar finding regarding regular and irregular German noun plural inflection see Penke and Krause (2002)

inflection see Penke and Krause (2002).
${ }_{5}^{5}$ The material contained 12 infrequent irregular participles (mean participle frequency 4.1), 12 frequent irregular participles (mean participle frequency 411.5), 14 infrequent regular participles (mean participle frequency 3.4), and 11 frequent regular participles (mean participle frequency 240.7).
} 
TABLE I

Information on German aphasic subjects

\begin{tabular}{|c|c|c|c|c|c|c|c|}
\hline Subj & Sex & Onset & Age at testing & Type of aphasia & Ethiology/localization & Handed-ness & Occupation \\
\hline MT & $\mathrm{m}$ & 04.1994 & 43 & Broca's & $\begin{array}{l}\text { CVA/including frontal areal of left arteria cerebri } \\
\text { media }\end{array}$ & right & social worker \\
\hline PB & $\mathrm{m}$ & 07.1990 & 53 & Broca's & CVA/left a.c.m. & right & engineer \\
\hline MB & f & 07.1993 & 63 & Broca's & CVA/including frontal area of left a.c.m. & right & seamstress \\
\hline WR & $\mathrm{m}$ & 02.1975 & 49 & Broca's & Tumour resection left & right & mechanic \\
\hline $\mathrm{KH}$ & $\mathrm{m}$ & 12.1995 & 62 & Broca's & CVA/left a.c.m. & right & bricklayer \\
\hline WW & $\mathrm{m}$ & 11.1989 & 62 & Broca's & CVA/left a.c.m. & right & civil servant \\
\hline HR & $\mathrm{m}$ & 1994 & 66 & Broca's & CVA/left a.c.m. & right & civil servant \\
\hline $\mathrm{JZ}$ & $\mathrm{f}$ & 05.1995 & 22 & Broca's & CVA/left a.c.m. & right & housewife \\
\hline $\mathrm{AH}$ & $\mathrm{f}$ & 10.1988 & 31 & Broca's & CVA/ including frontal area of left a.c.m. & right & hair dresser \\
\hline $\mathrm{HV}$ & $\mathrm{m}$ & 01.1983 & 64 & Broca's & & right & technician \\
\hline GB & $\mathrm{m}$ & 09.1988 & 51 & Broca's & CVA/left a.c.m. including Broca's area & right & teacher \\
\hline MJ & $\mathrm{m}$ & 04.1994 & 55 & Broca's & CVA/left & right & engineer \\
\hline FW & $\mathrm{m}$ & 1991 & 33 & Broca's & haemorrhage/left & right & locksmith \\
\hline
\end{tabular}

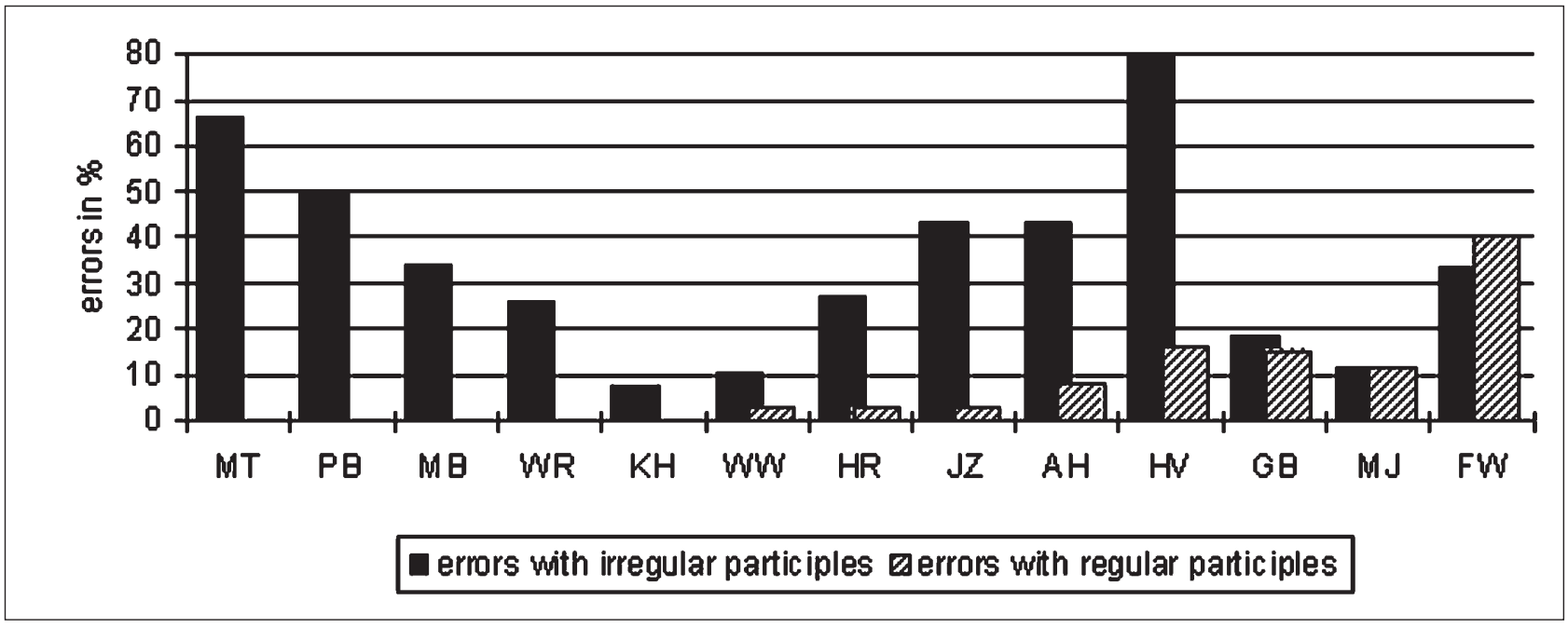

Fig. 1 - Error rates for the production of regular and irregular German participles in 13 subjects with Broca's aphasia. Error rates were calculated as follows ${ }^{6}$ :

$\Sigma$ incorrectly inflected regular (respectively irregular) participles $\times 100$

$\Sigma$ analysable regular (respectively irregular) participles

similarly affected by the frequency of the participle form: the mean error rate for infrequent $(8.3 \%)$ and frequent participles $(11.4 \%)$ did not differ significantly $[t(12)=.970, p=.351]$.

We furthermore analyzed the results of a re-test of the original experiment that was conducted with four of the subjects (subjects GB, MJ, PB, and WW) 13 to 16 months after the first testing. The re-test confirmed the findings of the original experiment. Again, regular participle inflection was largely unimpaired (mean error rate 6.8\%) whereas all four subjects experienced significantly more problems with irregular participles (mean error rate

${ }^{6}$ Forms that were not overtly marked as participles, i.e. forms which were neither marked with the prefix $g e$-, nor with the participle suffixes $-t$ or $-n$, nor with an ablauting stem, were not included in this analysis. A produced participle form was counted as incorrect if a wrong ending was used or if the ending was omitted. The analysis focuses on the correctness of the participle ending. Therefore 8 instances among the 461 analysable participles for irregular verbs where the ablauting stem was correctly produced but the participle ending was wrong (e.g., fecht - gefochtet cases with incorrect ablaut but correct irregular ending (e.g., flecht geflechten instead of geflochten 'braided') were counted as correct.
$20.9 \%)[t(3)=7.256, p=.005]^{7}$. As in the original study, errors with irregular participles were strongly dependent on the frequency of the irregular participle form: the mean error rates for infrequent irregular participles was $31.9 \%$ and dropped significantly to $4.2 \%$ for frequent irregular participles $[t(3)=6.255, p=.008]$. An individual comparison of those irregular participles that were incorrectly produced in the original test and the retest by these four subjects revealed that only 12 of the 32 incorrect forms of the original study were also incorrectly produced in the re-test. This indicates that the problems with irregular participles are not due to a loss of these forms in the mental lexicon.

Summarizing our main result on German participle inflection, it is irregular but not regular

\footnotetext{
${ }^{7}$ Interestingly, whereas subjects GB and MJ displayed no difference between regular and irregular participles in the first experiment, they both had considerably more problems with irregulars (error rates $28.2 \%$ and $18.4 \%$ respectively) than with regulars ( $8.6 \%$ and $5.6 \%$ respectively) in the re-test.
} 
TABLE II

Information on Dutch aphasic subjects

\begin{tabular}{|c|c|c|c|c|c|c|c|}
\hline Subj & Sex & Onset & Age at testing & Type of aphasia & Ethiology/localization & Handed-ness & Occupation \\
\hline AR & $\mathrm{m}$ & 10.1991 & 51 & Broca's & CVA/left frontotemporal & right & mechanic \\
\hline $\mathrm{CO}$ & $\mathrm{f}$ & 10.2000 & 57 & Broca's & CVA/left frontal & right & cleaner \\
\hline $\mathrm{HU}$ & $\mathrm{m}$ & 10.1994 & 55 & Broca's & CVA/left dorsal a.c.m. & right & fiscalist \\
\hline $\mathrm{KE}$ & $\mathrm{m}$ & 10.1997 & 62 & Broca's & CVA/left capsula interna & right & grocer \\
\hline KL & $\mathrm{f}$ & 09.2000 & & Broca's & CVA/left a.c.m. & right & florist \\
\hline NI & $\mathrm{m}$ & 08.1998 & 63 & Broca's & CVA/left a.c.m. & right & druggist \\
\hline RE & $\mathrm{f}$ & 02.1999 & 46 & Broca's & CVA/left parieto-occipital & right & cleaner \\
\hline $\mathrm{AD}$ & $\mathrm{f}$ & 1999 & 52 & Broca's & CVA/left a.c.m. & right & administration \\
\hline $\mathrm{AN}$ & $\mathrm{m}$ & 1984 & 73 & Broca's & CVA/left & right & administration \\
\hline MG & $\mathrm{m}$ & 2002 & 51 & Broca's & CVA/left & right & salesman \\
\hline $\mathrm{Z}$ & $\mathrm{m}$ & & & Broca's & & right & \\
\hline JW & $\mathrm{m}$ & 2000 & 41 & Broca's & left CVA & right & \\
\hline
\end{tabular}

TABLE III

Information on Dutch experimental material

regular past participles

\begin{tabular}{lll}
\hline Long version & 32 infrequent: & $\varnothing$ participle frequency 21 \\
& 35 frequent: & $\varnothing$ participle frequency 282 \\
short version & 15 infrequent: & $\varnothing$ participle frequency 23 \\
& 15 frequent: & $\varnothing$ participle frequency 325
\end{tabular}

irregular past participles

18 infrequent: $\varnothing$ participle frequency 22

33 frequent: $\quad \varnothing$ participle frequency 306

10 infrequent: $\quad \varnothing$ participle frequency 28

20 frequent: $\quad \varnothing$ participle frequency 359

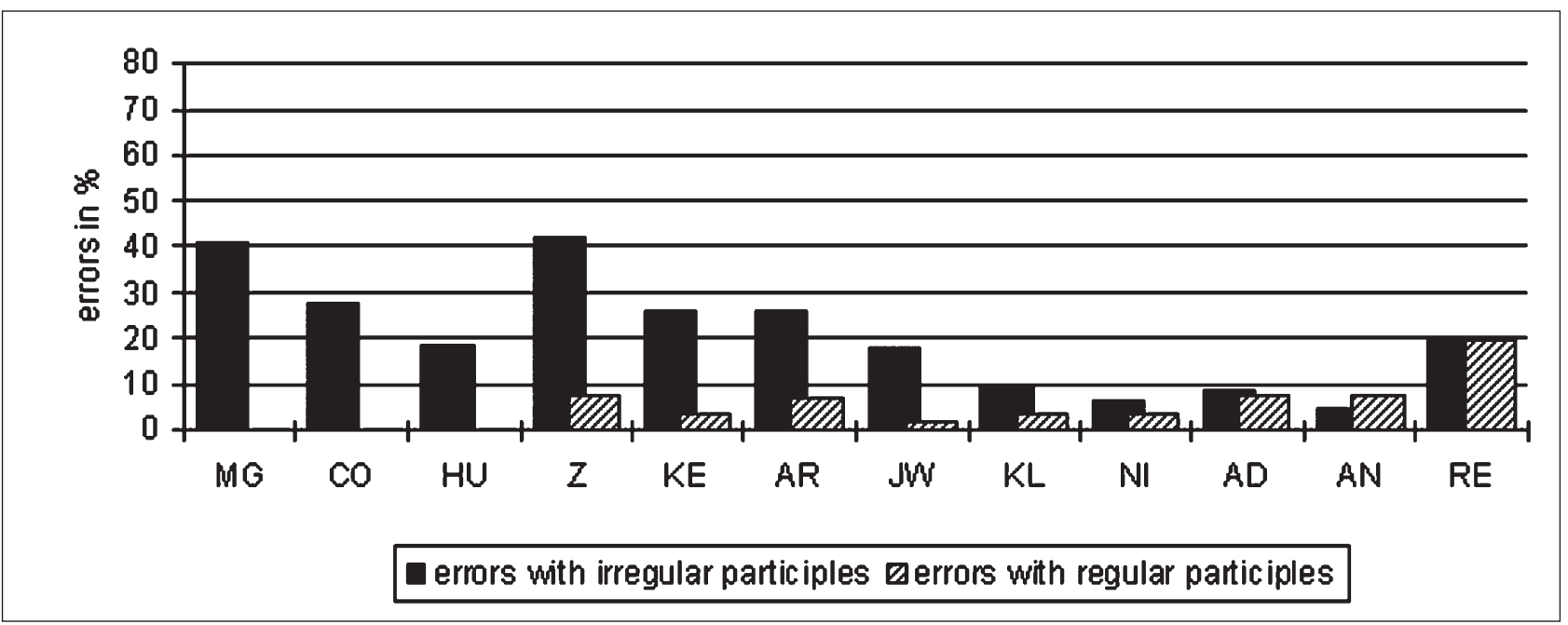

Fig. 2 - Error rates for the production of regular and irregular Dutch participles in 12 individuals with Broca's aphasia.

participle inflection that is selectively affected in German Broca's aphasia.

\section{Regular and Irregular Participles in Dutch Broca's Aphasia}

This finding was confirmed by an elicitation study on Dutch past-participle inflection that was conducted with 12 right-handed Dutch subjects with Broca's aphasia who were diagnosed by the Dutch version of the Aachener Aphasie Test (Graetz et al., 1992) (for more information on the subjects see Table II).

Comparable to the German experiment, the Dutch subjects were asked to transform a given third person plural present tense form (e.g., $Z i j$ vlechten. 'They braid') into a participle form (Zij hebben __?_[gevlochten]. 'They have braided').
Frequency of participle forms was carefully controlled for and the material consisted of both frequent and infrequent participles that were randomized (see Table III for more information) ${ }^{8}$. The experiment was run after a short practice-phase familiarizing the subjects with the task. Subjects' utterances were audio-taped and transcribed by the experimenters, all native speakers of Dutch.

Figure 2 presents the error rates for regular and irregular participles for the 12 Dutch aphasic subjects. Like the German aphasic subjects, the

\footnotetext{
${ }^{8}$ The experiment was run by our Dutch colleagues Roelien Bastiaanse, Peter Hagoort, Hermann Kolk, and Esther Ruijgendijk during other experimental investigations they carried out with their Broca's aphasic subjects. Five of investigations they carried out with their Broca's aphasic subjects. Five of
the aphasic subjects could be tested with a long version of this experiment that consisted of 67 regular verbs and 51 irregular verbs. Due to time restrictions, seven of the aphasic subjects (AR, CO, HU, KE, KL, NI, and $\mathrm{RE}$ ) could only be tested with a shorter version of the experiment which included 30 regular and 30 irregular verbs of the longer version.
} 
Dutch aphasic subjects were very successful in producing regular inflected participles with a mean error rate of only $5 \%$, but experienced significantly more problems in irregular participle formation (mean error rate $20.7 \%$ ) $[t(11)=3.801, p=.003]$. Moreover, not a single subject displayed a selective deficit with regular inflection, whereas for seven subjects (MG to JW) the reverse held: the production of irregular participles was impaired whereas regular participles were basically spared. In total the Dutch subjects produced 86 incorrectly inflected participles for irregular verbs. 85 of these errors were over-generalizations of the regular pattern of participle formation to irregular verbs (i.e. spin - gespint instead of gesponnen 'spin'). This indicates that regular inflection is unimpaired and can be productively applied to form participles.

\section{Discussion}

The data on Dutch and German Broca's aphasia show that a selective deficit with regular inflection is not a characteristic sign of Broca's aphasia across languages. Despite the close similarities between the Dutch and German systems of pastparticiple inflection and the English past-tense inflection, not a single one of the tested subjects with agrammatic Broca's aphasia displayed a selective deficit with regular inflection. On the contrary, most of the aphasic subjects experienced more problems with irregular inflection, whereas regular inflection was largely spared.

Our findings correspond to results from an elicitation study on Swedish past-tense morphology that was conducted with a fluent bilingual FinnishSwedish woman (JS) suffering from agrammatic Broca's aphasia due to a left anterior infarct (Ahlsén, 1994; Laine et al., 1994). Whereas JS succeeded in producing correct $-d e$ inflected past tense forms for $90 \%$ of the 39 presented regular verbs, her correctness score for irregular past tense forms (e.g., infinitive knyt 'to knot' - past tense knöt) was only 45\% (9 out of 20). Moreover, her errors resulted in over-regularizations of the regular past tense affix - de to irregular verbs (e.g., knytade instead of knöt). Good performance with regular inflectional systems such as subject-verb agreement inflection was for instance also reported in studies with Broca's aphasic speakers of Dutch (Haarmann and Kolk, 1994), Italian (Bates et al., 1991a), and Hebrew (Friedmann and Grodzinsky, 1997). These studies confirm that a deficit with regular inflection - as in English Broca's aphasia - is not a characteristic sign of agrammatic Broca's aphasia across languages.

How can we account for the differences between German/Dutch- and English-speaking subjects with Broca's aphasia regarding inflectional deficits? Bird et al. (2003) suggest that the selective vulnerability of regular past-tense forms in English-speaking subjects with Broca's aphasia might be due to a greater phonological complexity of regular compared to irregular past-tense forms. Since regular past-tense forms, unlike most irregulars, involve the addition of phonetic material ([t], [d], or [Id]) they place greater demands on the phonological system. In Dutch and German this difference is reversed: here, irregular past participles are phonologically more complex than regulars, because the production of irregular pasttense forms leads to the addition of a new syllable to the verb stem (trink-getrunken 'drink'), whereas the production of regular participles only involves addition of a new phoneme (bell-gebellt, blafgeblaft 'bark'). However, although these differences in phonological complexity might account for the selective vulnerability of irregular participles compared to regular ones observed in our data, they do not explain the large differences between the correctness scores for regular forms in English and German/Dutch. Despite the fact that all these forms are of similar phonological complexity (they add an extra phon $[\mathrm{t}]$ in the past, compare English danced with German getanzt and Ducht gedanst $)^{9}$, reported mean correctness scores for English agrammatic speakers range only between $20 \%$ and $50 \%$ with individual scores never surpassing 80\% (Ullman et al., 1997; Bird et al., 2003; Faroqi-Shah and Thompson, 2003, 2004). The mean correctness scores for German and Dutch regular participles, in contrast, are $91.2 \%$ and $95 \%$, respectively, and only one of the 25 tested subjects showed a correctness score of less than $80 \%$ (German subject FW). Moreover, if a phonological deficit were responsible for the impairment of irregular participle inflection in German and Dutch Broca's aphasia, we would expect that errors in the production of irregular participles result in uninflected stem forms. While the production of uninflected stems is a common error type in English agrammatic subjects (c.f., Ullman et al., 1997; Bird et al., 2003; Faroqi-Shah and Thompson, 2004), this error only rarely occurs in our German and Dutch data ${ }^{10}$. In contrast to English, most errors with irregular participles in German and Dutch agrammatic subjects result in over-applications of the regular affix -t. This finding cannot be explained with the phonologicaldeficit account. Following Bates et al. (1987, 1991b), we instead suggest that the different impairments observed in English versus German/Dutch Broca's aphasia result from language specific differences in the status and importance of inflectional systems. In so-called analytic languages like English, which show very

\footnotetext{
${ }^{9}$ In past-tense forms for regular verbs that already end in a coronal stop in the stem a syllable is added (want - wanted). This however also holds for German regular verbs (rett- - gerettet 'rescue').

${ }^{10}$ We could show that the rare omission errors that do occur in participle formation in German agrammatic Broca's aphasia are restricted to a specific phonological context, namely when the regular participle ending $-t$ is affixed to a verbal stem already ending in a dental stop (c.f., Janssen and Penke 2002; Grijzenhout and Penke, 2005).
} 
reduced inflectional systems, speakers with Broca's aphasia tend to omit inflectional endings, thus mimicking a deficit with regular inflection. Aphasic speakers of more synthetic, inflecting languages like German will, by contrast, generally tend to produce inflectional endings and display no evidence for a selective deficit with regular forms.

Whereas performance with regular inflection is markedly different in English versus German/Dutch Broca's aphasia, irregular inflected forms seem to be similarly impaired across languages. The studies on Dutch, English, German and Swedish irregular past-tense and participle formation all report deficits with irregular inflected forms. Moreover, in English (c.f., Bird et al., 2003) as well as in German and Dutch, individual error-rates display a wide spectrum between basically spared performance and massive impairments. In Section 4, we will present a model that accounts for the impairment with irregular inflected forms observed across languages.

The observation that regular inflection is not selectively impaired in German and Dutch Broca's aphasia provides evidence against Ullman's suggestion that regular inflection is crucially subserved by Broca's area. Unfortunately we do not have information on the precise localization of the brain lesions of the German and Dutch Broca's aphasics under study here, but have to rely instead on medical reports. Therefore - although Broca's aphasia is generally caused by a lesion encompassing Broca's area - we cannot exclude the possibility that Broca's area is not affected in all of the tested subjects. Note, however, that according to the information available on seven of the Dutch Broca's aphasics, Broca's area is very likely to be affected in subjects AR and CO (Peter Kok, p.c.). A lesion encompassing Broca's area can also be assumed for the German subjects MT, MB, $\mathrm{AH}$ and GB who suffered lesions of left frontal brain areas. And Broca's area is also lesioned in the Finnish-Swedish woman (JS) (Matti Laine, p.c.). Nevertheless, none of these subjects display a deficit with regular inflection, but in all of them irregular inflection is impaired whereas regular inflection is largely intact ${ }^{11}$. We consider it highly improbable that a deficit with regular inflection, described as characteristic for Broca's aphasia by Ullman, does not show up in a single case out of 25 arbitrarily chosen individuals suffering from this disorder.

Further evidence against a crucial role of Broca's area that is specific for regular inflection comes from two recent imaging studies on regular and irregular inflection in German. In an eventrelated functional magnetic resonance imaging (ER-fMRI) study on regular and irregular German past participles and noun plurals, Beretta et al.

\footnotetext{
${ }^{11}$ While this does not hold for the original experimental data of GB,
} irregular participles were selectively affected for this subject in the re-test.
(2003) found that producing irregular forms activated extensive cortical areas, including Broca's area, whereas Broca's area "showed little evidence of activation" (p. 80) during the production of regular forms. Sach et al. (2004) reported activation data related to the production of regular and irregular German past-tense and past-participle forms that come from a positron emission tomography (PET) study conducted with 12 German unimpaired right-handed speakers. A comparison of the activations related to the production of regular and irregular inflected verb forms yielded no significant differences in regional cerebral blood flow (rCBF) increases. In comparison to the baseline condition, where correctly inflected verbs had to be inserted into a sentence frame, the production of both regular and irregular inflected verb forms led to significant $\mathrm{rCBF}$ increases in the left inferior frontal gyrus (Brodmann's area 45), the right nucleus lentiformis and thalamus, and the superior medial cerebellum. Sach et al. concluded that this "pattern of results speaks against distinct and specific neural correlates of regular and irregular inflection" ( $p$. 536). Although there are some discrepancies between the results reported in these two studies they agree in that they provide no evidence for the assumption that regular - and only regular inflection - is subserved by Broca's area.

\section{A Neural Network Simulation of German PARTICIPLE FORMATION}

To investigate the nature and localization of the processes and mechanisms underlying participle inflection we modeled the results of the German agrammatic aphasic speakers with a connectionist neural network model.

\section{Network Structure}

The model was based on the premise that the adult language processing system is shaped by development through the interactions of multiple constraints: pre-determined basic neural structures, the statistical structure of the language environment, and mechanisms of experiencedependent neural development such as the establishment of new synapses. The latter constraint was implemented in the model by allowing it to change its structure in response to the learning task through a constructivist process.

The task of the model was to learn German participle inflection. The input to the model consisted of a phonological representation of the verb stem (see below). The output of the model was not phonological but consisted of classes that determined how the participle is formed from the verb stem. In this way, the difficulty of learning regular and different irregular forms in the model 


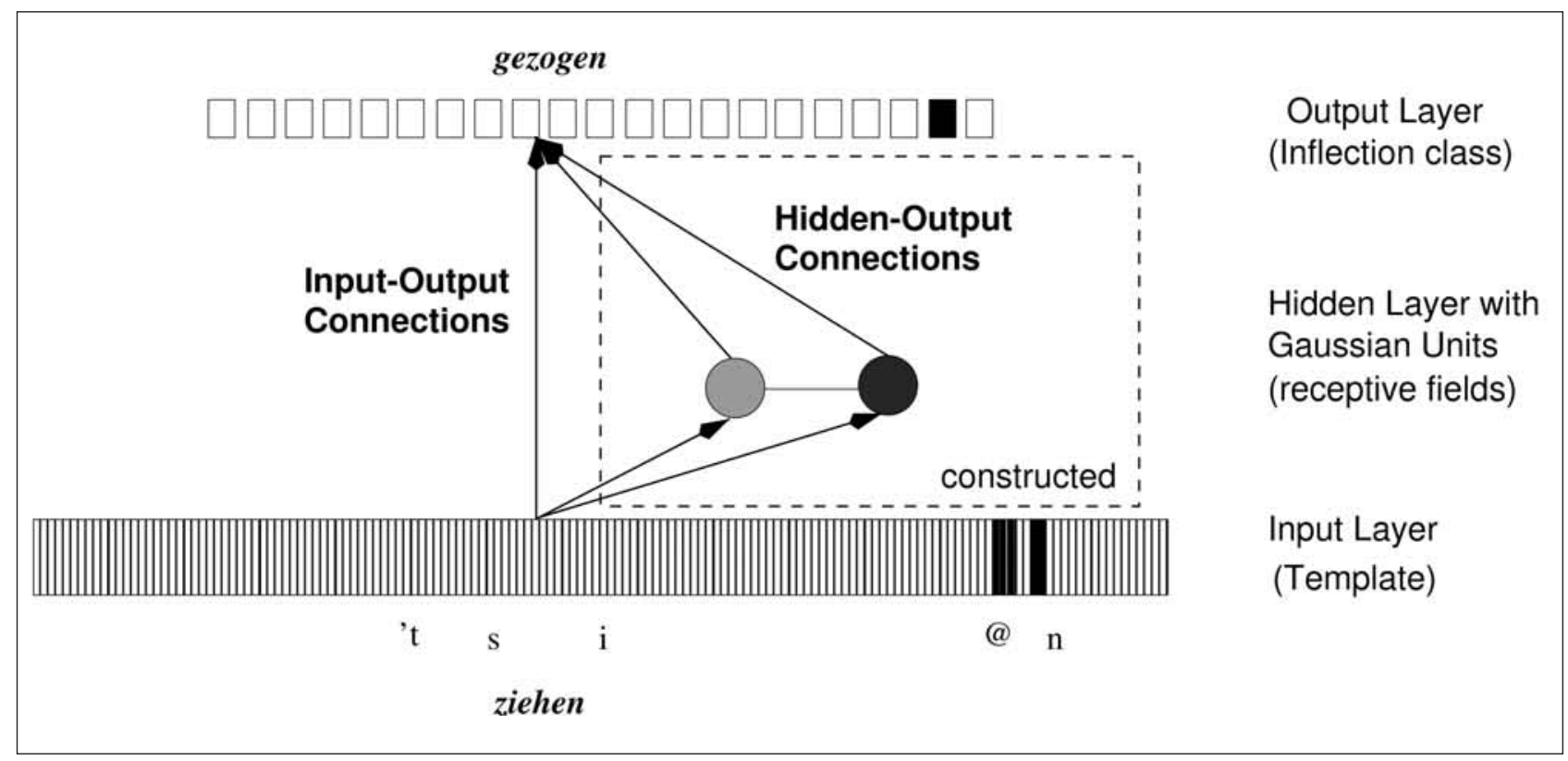

Fig. 3 - The neural network model.

became independent from the specific transformation of the verb (e.g., suffixation or stem change or both), allowing us to investigate the role of other factors (such as verb distribution and frequency) in the impaired processing of inflections. We identified 21 different classes that determine in which ways participles are formed. One is the regular class (no stem change, ending $-t$ ), others are, for example, /I/ $\rightarrow / \mathrm{U} /$ with ending -en (singen $\rightarrow$ gesungen 'sing'), /I/ $\rightarrow / \mathrm{O} /+$ en (schwimmen $\rightarrow$ geschwommen 'swim'), and /E/ $\rightarrow / \mathrm{O} /$ en (nehmen $\rightarrow$ genommen 'take').

The model's initial architecture consisted of an input and an output layer that were fully interconnected (Figure 3). During the learning of the task, new hidden units were gradually inserted until all inflections had been successfully learned. The hidden units in this model had Gaussian activation functions that acted as receptive fields in the phonological input space. The hidden layer developed in the following way: the model was trained by adjusting the connection weights in its current architecture (with the quickprop algorithm; Fahlman, 1988) until learning did not reduce the error any further. Then a new hidden unit was inserted and training proceeded by adjusting the connection weights in this new architecture. The new hidden unit was inserted in a region of the input space that caused the highest error during training. Existing receptive fields in this area were shrunk, and the new unit was inserted close to them (see also Fritzke, 1994). The idea here is that a receptive field that produces a high output error is inadequate (because it covers inputs with conflicting outputs), and more structural resources are needed in that area. In this way the insertion of a new unit in effect led to a more 'fine-grained' resolution in that area of the input space.
To illustrate this concept, Figure 4 shows a hypothetical start and end state for the distribution of the hidden unit receptive fields in the phonological input space. In this space, similar sounding verbs are located close together. The model tries to learn the participles of all verbs. Initially (A), the same receptive field responds to both hören and schwören ('hear' and 'swear'), and another to lachen and machen ('laugh' and 'make'). For the latter pair no problem arises because both verbs are regular in German. However, hören is regular (participle gehört) whereas schwören is irregular (participle geschworen). Thus, both verbs activating the same receptive field will lead to output error. The responsible receptive field accumulates error and, in the process of learning, is split (B). As a consequence, the final structure of the network (the number of hidden units and their positions) reflects the characteristics of the learning task (the distribution of verb classes and their frequency in the training data). This process of task-dependent structural development aimed to mimic on an abstract level the experience-dependent development of cortical structures during cognitive development (e.g., Quartz and Sejnowski, 1997).

The training data for the model was extracted from the CELEX database (Baayen et al., 1993). From the initial set of 3,015 German participles in CELEX errors and homophones were removed, and different prefixed forms of the same verb were combined into one type (e.g., the simplex verb fahren, 'drive', occurred in 28 composite forms such as wegfahren 'drive away' or radfahren 'cycle' that were combined into one). Further, all verbs with a token frequency of below 5 were removed, with the exception of the verbs used in the testing of the German aphasic speakers. 


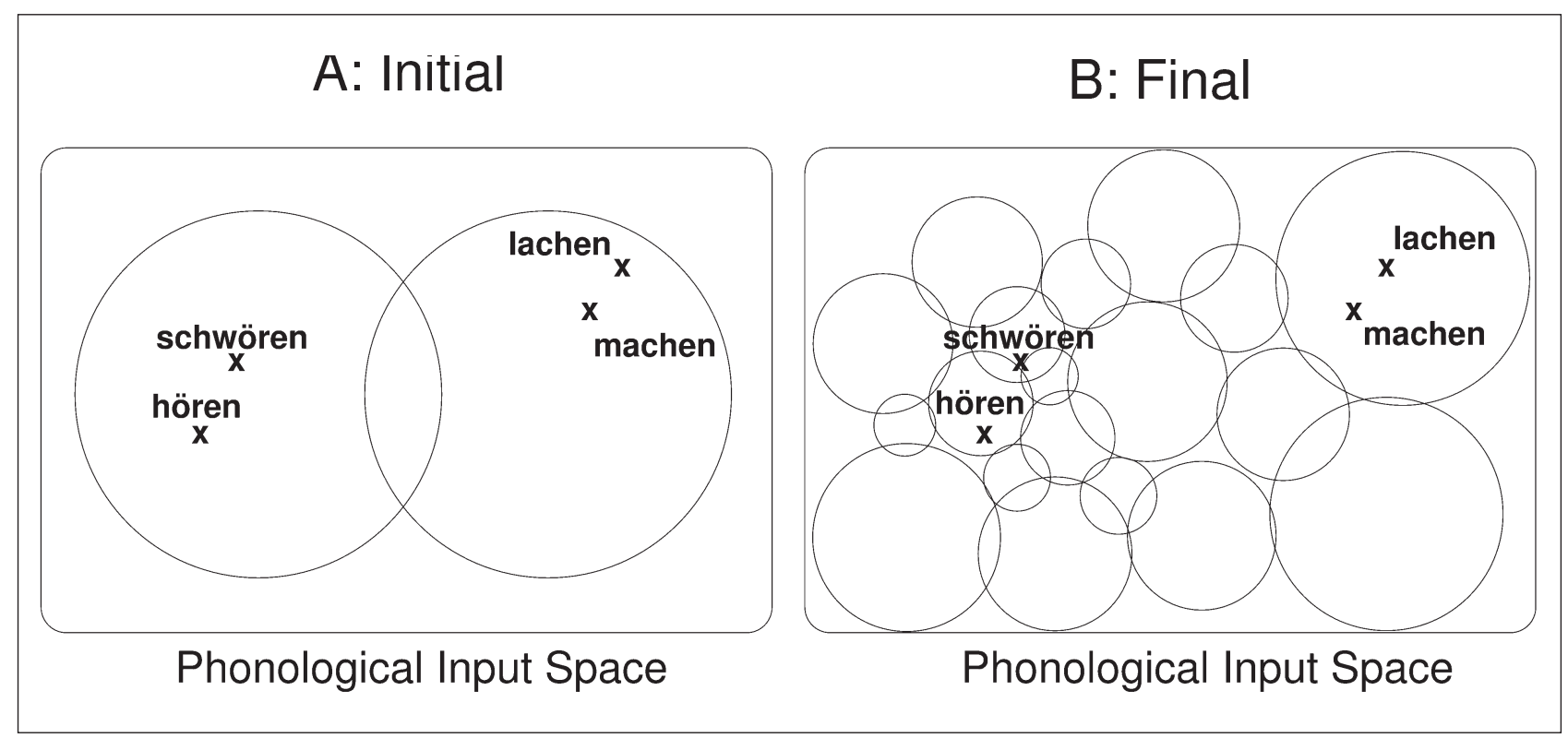

Fig. 4 - Illustration of the development of an experience-dependent architecture of the model.

From the resulting corpus of 664 verb types, 20,000 tokens were randomly extracted according to frequency. The resulting data set had the following distribution: regular verbs: $78.0 \%$ types, $46.5 \%$ tokens; irregular verbs: $20.2 \%$ types, $48.5 \%$ tokens $^{12}$.

For the input to the model, each phoneme was represented by a 7-bit phonetic feature vector, representing features such as high, low, and frontal for vowels, and coronal, nasal, and voiced for consonants. This representation was entered into a three-syllabic template of the form XCCCVVCC for each syllable (X, stressed; $\mathrm{C}$, consonant; $\mathrm{V}$, vowel). The verbs were right-aligned in this template. The resulting network had 150 input units (three syllables with seven phonemes each represented by seven features, plus one stress-bit per syllable), and 21 output units for the 21 inflection classes. Five networks were trained with different random initial weight settings. An output class was counted as correct when the corresponding unit, but no other unit, had an activation value over 0.7 .

After an average of 2,386 sweeps through the training data the model had learned to inflect all verbs correctly. The final structure of the model consisted of an average of 180 hidden unit receptive fields (ranging from 119 to 211). The distribution of hidden units revealed a significant difference between regular and irregular verbs: on average, each regular verb shared a receptive field with 5.1 other verbs, whereas an irregular shared its receptive field with only 0.79 other verbs. Thus, receptive fields for irregular verbs had become more highly specialized than those for regular

\footnotetext{
${ }^{12}$ The remaining verbs were mixed verbs that are not discussed here.
}

verbs. It is important to note that this unequal distribution of resources is not due to an a priori distinction between regular and irregular verbs but develops solely based on the inflection task learned by the model. This result illustrates the advantage of the experience-dependent adaptation of the network architecture: no a priori decision had to be made about the number and location of hidden units, but the model developed larger receptive fields for regular verbs and small, fine-grained receptive fields for the more difficult irregular verbs. One determining factor for resource allocation was the size of inflection classes counted in tokens: the smaller the class size in tokens, the more hidden units were allocated per verb in that class because they formed harder to learn exceptions (correlation 'class size in tokens' with 'hidden units per class' $=-0.79$ ).

\section{Lesioning the Network}

In order to investigate the internal representations developed by the model and to simulate performance of the German Broca's aphasic speakers, the fully trained network models were lesioned by randomly removing connection weights. It was assumed that the removal of connections in the network model corresponds to the destruction of neural tissue in the brain by stroke or injury. The percentage of removed connections proceeded from $0 \%$ to $100 \%$ in $5 \%$ steps, and each of these 20 steps was repeated 200 times with different random weights.

The result of the lesioning simulation is shown in Figure 5. A higher degree of lesioning unsurprisingly generally led to more impaired performance. Like with the German aphasic speakers, the lesioned model never showed a 


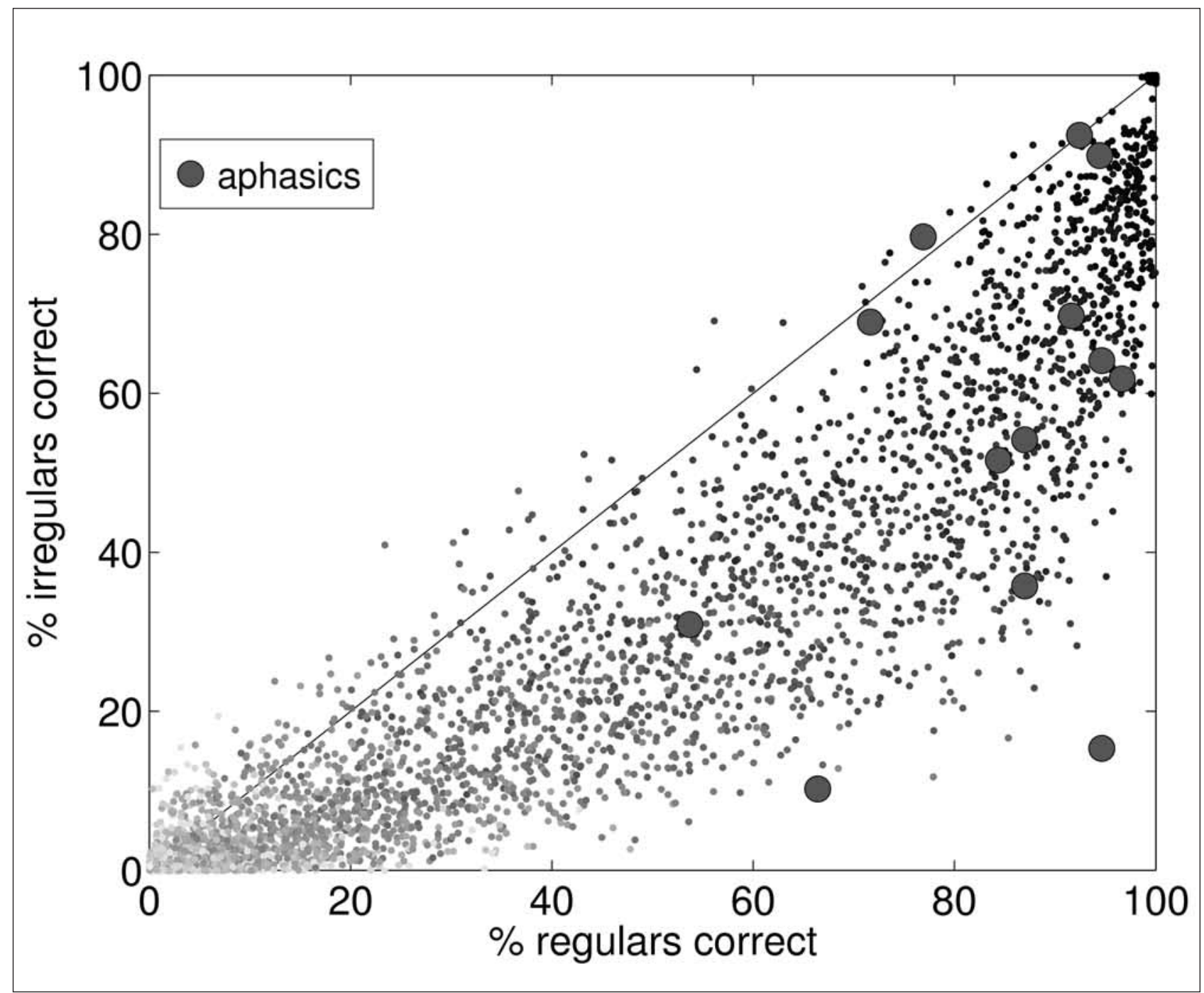

Fig. 5 - Results of lesioning the model. Grayscale indicates degree of lesioning (black $=0 \%$, light gray $=100 \%)$. The diagonal indicates equal amounts of regular and irregular impairment. Performance of the 13 German aphasic subjects is also plotted.

selective sparing of irregular inflection with a breakdown of regular inflections. Instead, in most cases impairment of irregulars was stronger than that of regulars (below the diagonal). The data for the 13 German Broca's aphasic speakers are also displayed $^{13}$. All aphasic data are within the range of performance predicted by the simulations, showing that although there is variability in the performance of the aphasic patients differently lesioned models can simulate the performance of each of them. The model is not over-general, however: like in the aphasic patients, a selective sparing of irregulars with a breakdown of regular inflections did not occur in any of the 4,000 lesioning trials.

Why does global lesioning in the model lead to a profile in which irregular participles are more

\footnotetext{
${ }^{13}$ To allow for a better comparison between aphasic subjects and the model we here counted all incorrect forms and null-reactions, where the aphasic speakers produced no participle, as wrong. This is because in the model, not inflecting a verb is expressed by failure to reach the threshold level for unit activation of all output units and is also counted as wrong.
}

impaired than regulars? An answer to this question can be found by analyzing the internal structure of the model. Effectively, an output in the model is generated through the interactions of two pathways: the direct pathway from the input to the output layer (IO), and the pathway via the developed hidden to the output layer (HO). However, these pathways imply neither separate mechanisms nor local separation. Instead, they are based on two distinct representations of the verb infinitive: distributed and quasi-localist. The phonological representations of the verb on the input layer are distributed, and the representations for similar sounding verbs overlap. These representations facilitate generalization to similar stems, but at the same time overlapping representations become activated for verbs that are inflected in different ways (such as hören and schwören). By contrast, the hidden representations that develop in the model are quasi-localist: one receptive field is activated by one or a small number of verbs, and due to the experience-dependent development of the hidden layer, often all verbs activating a 
receptive field belong to the same inflection class. The activation of a receptive field can thus override conflicting information arising from the distributed input representations. Analysis of the network structure revealed that this additional representation is allocated mainly to the more difficult to learn irregular verbs. As a consequence, lesioning the network primarily affects irregular verbs that rely on both the distributed phonological and the quasi-localist representations, whereas regular forms are produced based on the distributed phonological representations alone. In effect, this result suggests that in the German aphasic speakers irregular forms are selectively damaged because they require more processing resources than regular verbs.

Frequency effects for irregulars arise in the model because frequent irregulars make use of the direct IO connections without relying on the added hidden representations. The IO pathway makes uses of the distributed phonological representations and is therefore more robust to partial lesioning (because loss of part of the distributed information still allows the correct form to be produced) than the HO pathway which relies on quasi-localist representations (and where lesioning of one connection from representation to output results in loss of this inflection). Less frequent irregulars rely additionally on this developing HO pathway. As a consequence, lesioning affects primarily those less frequent irregulars. For regular verbs there is no such frequency effect because all of them are generated in the direct IO pathway.

\section{DISCUSSION}

The results on German and Dutch pastparticiple inflection presented in Section 3 show that deficits for regular inflection are not a characteristic sign of agrammatic Broca's aphasia across languages. We suggest that the observed differences between English and German/Dutch aphasic speakers are due to language specific differences in the status and importance of inflectional systems. Whereas in an analytic language such as English inflectional endings tend to be omitted in Broca's aphasia, in languages with more expanded inflectional systems omissions of inflectional markers are rare and aphasic speakers try hard to produce the correct markings. This view follows a suggestion by Bates et al. (1987, 1991b) who proposed that limitations in processing capacities result in different error patterns in aphasic speech depending on the grammatical and morphological characteristics of the language system. These language-specific differences account for the observation that regular past-tense inflection is selectively impaired in English, whereas regular past-participle inflection is selectively spared in German and Dutch. While no current connectionist models take the entire grammatical and morphological system into account, the model presented here explains the cross-linguistically observed deficits for irregular inflected verbs with the unequal allocation of processing resources in a developmental process. It also demonstrates how and why a limitation in processing capacity will primarily affect irregular forms: irregular forms crucially rely on the quasilocalist hidden representations constructed in the learning of the system. These quasi-localist representations are stronger affected by global damage than the distributed phonological representations used by regular forms. Damage that affects one or more of these hidden quasi-localist representations for irregulars will lead to an overgeneralization error because the regular output represented in the distributed phonological inputoutput-pathway is less vulnerable to damage and will thus yield an incorrectly regularized output. The model also accounts for the observed frequency effect for German irregular participles: infrequent irregular participles are more impaired since they are more dependent on the quasi-localist hidden representations than frequent irregular participles.

Our model differs from a previous connectionist model of aphasic processing (Joanisse and Seidenberg, 1999) in that it does not rely on a semantic component to produce irregular forms. The Joanisse and Seidenberg (1999) model has effectively two pathways, a phonological and a semantic one. In their model, selective regular impairment follows from damage to the phonological system, whereas irregular deficits arise from damage to the semantic system. Their model thus makes the strong predictions that a semantic deficit necessarily leads to deficits with irregular inflections, and that deficits with irregular inflections imply a semantic deficit. However, while several studies have shown associations between semantic and irregular inflection deficits (e.g., Marslen-Wilson and Tyler, 1998; Patterson et al., 2001), other research has shown that semantics and irregular inflection processing dissociate in priming tasks and ERP measurements in healthy subjects (Marslen-Wilson and Tyler, 1998; Marslen-Wilson et al., 2000) as well as in patients with intact semantics but impaired irregular inflection (Miozzo, 2003) and others with impaired semantics but intact irregular inflection (Tyler et al., 2004). This evidence points against a causal connection between semantics and irregular inflection and thus seems more in line with a system like our model in which irregular inflection does not rely on a semantic component.

An alternative account for the difficulties that German aphasic speakers experience with the production of irregular participles is that processing limitations lead to problems in lexical access. Less frequent irregular participles will have weaker 
memory representations, and therefore access to these forms will fail more often, resulting in overgeneralizations of the regular affix. In our model, by contrast, lexical access is presupposed to be unimpaired, reflected in the presentation of the infinitive form at the input layer. Further research will have to be conducted to differentiate between these two possibilities. Impaired lexical access in the model could for instance be simulated by adding noise to the input representations.

The neural network model demonstrates that we do not have to assume two distinctly localized inflectional processes or mechanisms that are selectively affected by brain damage in order to account for selective impairments as shown by the German and Dutch aphasic speakers. Instead, in the model a single associative mechanism that is based on two (dynamically constructed) representations is responsible for both regular and irregular forms. A selective impairment of irregular inflection can result from global damage to this system and does not depend on the lesioning of a specific brain region ${ }^{14}$. This finding corresponds to the observation that our aphasic subjects - as evident in their medical reports - show some variability in location and extend of brain damage. Nevertheless, they as well as the lesioned models display a relatively homogeneous impairment profile. Our suggestion that the grammatical deficits displayed by Broca's aphasic speakers are due to limitations in processing capacity has a long and vital tradition in aphasiology. Processing accounts have been proposed for instance by Friederici (1995), Kolk (1995), or Swinney and Zurif (1995). Proponents of processing accounts argue that the grammatical knowledge system is still unimpaired and can be put to use in Broca's aphasia. Moreover, they point out that the grammatical deficits observed in Broca's aphasia are not static but deteriorate or ameliorate depending on task demands or time constraints that lead to a lowering or raising of the processing load. Whereas the debate between proponents of 'competence-deficit' and 'processingdeficit' accounts is still not settled, it is by now nevertheless widely acknowledged that central components of the grammatical knowledge system are often unimpaired in Broca's aphasia (c.f., e.g., Grodzinsky, 2000 and the subsequent discussions). Thus Ullman's suggestion that the grammar component, including the rules for regular inflection, is critically related to Broca's area and consequently impaired in Broca's aphasia over-

\footnotetext{
${ }^{14}$ Note, however, that selective deficits based on global lesioning do not exclude the possibility of two qualitatively distinct inflectional components for regular and irregular inflections. For example, in Wunderlich's (1996) dualistic model inflectional affixes have independent entries in the mental lexicon just like any oter lexical element. Although dualistic, this menter does not presuppose a distinct and different localization of stored irregular forms and affixed regular forms, since the components of regular inflected forms such as verbs and affixes are both stored in the mental lexicon. The question whether inflections are processed by a single or by multiple mechanisms is not the focus of the present paper.
}

simplifies the findings that have been collected in aphasiology over the past years. Especially the cross-linguistic investigation of aphasic language disorders has played a major role in broadening and refining our knowledge on these disorders. Against this background we have tried to show that a selective deficit with regular inflection is not observed in German and Dutch Broca's aphasics. We have furthermore suggested that the aphasic and modeling data presented here offer compelling evidence that the selective deficit of irregular participles observed in German and Dutch Broca's aphasics can be accounted for by a global processing deficit instead of the selective disruption of one of two distinctly localized processing mechanisms as claimed by Ullman.

Acknowledgments. The research reported in this paper was supported by German Science Foundation grant SFB 282/C8 to Martina Penke. We would like to thank Claudia Hegenscheidt for designing the material of the Dutch experiment. We are especially grateful to Esther Ruijgendijk, Herman Kolk, Peter Hagoort, and Roelien Bastiaanse for running the experiment with their Dutch aphasic subjects, and to Peter Kok for providing us with information on seven of the Dutch aphasic subjects. We would also like to thank the editors, Christian Fiebach and Ricarda Schubotz, as well as Sonja Kotz and an anonymous reviewer for their valuable comments and suggestions on an earlier version of this paper.

\section{REFERENCES}

AhLsÉn E. Cognitive morphology in Swedish: Studies with normals and aphasics. Nordic Journal of Linguistics, 17: 6173, 1994.

AleXANDER MP. Aphasia: Clinical and anatomic aspects. In Feinberg TE and Farah MJ (Eds), Behavioral Neurology and Neuropsychology. New York: McGraw-Hill, 1997.

Alexander MP, Naeser MA and Palumbo C. Broca's area aphasias: Aphasia after lesions including the frontal operculum. Neurology, 40: 353-362, 1990.

BAAYEN RH, PIEPENBROCK R and VAN RIJN H. The CELEX Lexical Database (CD-ROM). Philadelphia: Linguistic Data Consortium, University of Pennsylvania, 1993.

Bates E, Appelbaum M and Allard L. Statistical constraints on the use of single cases in neuropsychological research. Brain and Language, 40: 295-329, 1991a.

Bates E, Friederici A and Wulfeck B. Grammatical morphology in aphasia: Evidence from three languages. Cortex, 23: 545574, 1987.

Bates E, Wulfeck B and MacWhinney B. Cross-linguistic research in aphasia: An overview. Brain and Language, 41: 123-148, 1991b.

Benedet MJ, Christiansen JA and Goodglass H. A crosslinguistic study of grammatical morphology in Spanish- and English-speaking agrammatic patients. Cortex, 34: 309-336, 1998.

Beretta A, Campbell C, Carr TH, Huang J, Schmitt, LM, Christianson $\mathrm{K}$ and CAO Y. An ER-fMRI investigation of morphological inflection in German reveals that the brain makes a distinction between regular and irregular forms. Brain and Language, 85: 67-92, 2003.

Bird H, Lambon-Ralph MA, Seidenberg MS, McClelland JL and PATterson K. Deficits in phonology and past-tense morphology: What's the connection? Journal of Memory and Language, 48: 502-526, 2003.

Clahsen H. Lexical entries and rules of language: A multidisciplinary study of German inflection. Behavioral and Brain Sciences, 22: 991-1060, 1999.

Damasio AR. Aphasia. New England Journal of Medicine, 326: 531-539, 1992.

DRONKERS NF, REDFERN BB and KNIGHT RT. The neural architecture of language disorders. In Gazzaniga MS (Ed), 
The New Cognitive Neurosciences. Cambridge, MA: MIT Press, 2000.

FAHLMAN SE. Faster-learning variations on back-propagation: An empirical study. In Touretzky DS, Hinton GE and Sejnowski TJ (Eds), Proceedings of the 1988 Connectionist Models Summer School. San Mateo: Morgan Kaufmann, 1988.

FAROQI-SHAH Y and THOMPSON CK. Regular and irregular verb inflections in agrammatism: Dissociation or association? Brain and Language, 87: 9-10, 2003.

FAROQI-Shah Y and Thompson CK. Semantic, lexical, and phonological influences on the production of verb inflections in agrammatic aphasia. Brain and Language, 89: 484-498, 2004.

FRIEDERICI A. The time course of syntactic activation during language processing. Brain and Language, 50: 259-281, 1995.

FriEdmanN N and GrodzINSKY Y. Tense and agreement in agrammatic production: Pruning the syntactic tree. Brain and Language, 56: 397-425, 1997.

FRITZKE B. Fast learning with incremental RBF networks. Neural Processing Letters, 1: 2-5, 1994.

Graetz P, DE Bleser R and Willmes K. Akense Afasie Test. Lisse: Swets Zeitlinger, 1992

GriJzenhout J and PenKe M. On the interaction of phonology and morphology in German and Dutch first language acquisition and Broca's aphasia: The case of inflected verbs. Yearbook of Morphology 49-81, 2005.

GroDZINSKY Y. The neurology of syntax. Behavioral and Brain Sciences, 23: 1-71, 2000

HAARMANN HJ and KOLK HHJ. On-line sensitivity to subject-verb agreement violations in Broca's aphasics: The role of syntactic complexity and time. Brain and Language, 46: 493-516, 1994.

Huber W, Poeck K, Weniger D and Willmes K. Der Aachener Aphasie Test. Göttingen: Hogrefe, 1983.

JANSSEN U and PENKE M. Phonologically conditioned omissions of inflectional affixes in German Broca's aphasia. Brain and Language, 83: 99-101, 2002.

JOANISSE MF and SEIDENBERG MS. Impairments in verb morphology after brain injury: A connectionist model. Proceedings of the National Academy of Sciences of the USA, 96: 7592-7597, 1999.

Kehayia E, Jarema G and KadziElawa D. Cross-linguistic study of morphological errors in aphasia: Evidence from English, Greek, and Polish. In Nespoulous JL and Villiard P (Eds), Morphology, Phonology, and Aphasia. New York: Springer, 1990.

KolK H. A time-based approach to agrammatic production. Brain and Language, 50: 282-303, 1995.

Laine M, NiEMi J, KoIVUSELKÄ-SALLINEN P, AHLSÉN E and HYÖNä J. A neurolinguistic analysis of morphological deficits in a Finnish-Swedish bilingual aphasic. Clinical Linguistics and Phonetics, 8: 177-200, 1994.

MacWhinney B, Bates E and Kliegl R. Cue validity and sentence interpretation in English, German, and Italian. Journal of Verbal Learning and Verbal Behavior, 23: 127-150, 1984.

MacWhinney B and Bates E. The Crosslinguistic Study of Sentence Processing. Cambridge: Cambridge University Press, 1989.

Marslen-Willon WD, Csibra G, Ford M, Hatzakis H, Gaskell $\mathrm{G}$ and JoHnson MH. Associations and dissociations in the processing of regular and irregular verbs: Electrophysiological evidence. Journal of Cognitive Neuroscience, 12: Supplement, $55 \mathrm{E}, 2000$.
MARSLEN-WILSON WD and TYLER LK. Dissociating types of mental computation. Nature, 387: 592-594, 1997.

MARSLEN-WILSON WD and TYLER LK. Rules, representations, and the English past tense. Trends in Cognitive Sciences, 2: 428 435, 1998.

Menn L and OBLer LK. Cross-language data and theories of agrammatism. In Menn L and Obler LK (Eds), Agrammatic Aphasia: A Cross-Language Narrative Sourcebook (vol. II). Amsterdam: Benjamins, 1990.

Miozzo M. On the processing of regular and irregular forms of verbs and nouns: Evidence from neuropsychology. Cognition, 87: 101-127, 2003.

Niemi J, Laine M, Hänninen R and Koivuselka-Sallinen P. Agrammatism in Finnish: Two case studies. In Menn L and Obler LK (Eds), Agrammatic Aphasia: A Cross-Language Narrative Sourcebook (vol. II). Amsterdam: Benjamins, 1990.

Patterson K, Lambon-Ralph MA, Hodges JR and McClelland JL. Deficits in irregular past-tense verb morphology associated with degraded semantic knowledge. Neuropsychologia, 39: 709-724, 2001.

Penke M, Janssen U and Krause M. The representation of inflectional morphology: Evidence from Broca's aphasia. Brain and Language, 68: 225-232, 1999.

PENKE $M$ and KRAUSE M. German noun plurals: A challenge to the dual-mechanism model. Brain and Language, 81: 303-311, 2002.

PINKER S. Words and Rules. New York: Basic Books, 1999.

Pinker $S$ and Ullman M. The past and future of the past tense. Trends in Cognitive Sciences, 6: 456-463, 1997.

QUARTZ SR and SEJNOWSKI TJ. The neural basis of cognitive development: A constructivist manifesto. Behavioral and Brain Sciences, 20: 537-596, 1997.

SACH M, SEITZ RJ and InDEFREY P. Unified inflectional processing of regular and irregular verbs: A PET study. NeuroReport, 15: 533-537, 2004.

SwINNEY D and ZURIF E. Syntactic processing in aphasia. Brain and Language, 50: 225-239, 1995.

Tyler LK, DeMornay-Davies P, Anokhina R, Longworth C, Randall B and Marslen-Wilson W. Dissociations in processing past tense morphology: Neuropathology and behavioural studies. Journal of Cognitive Neuroscience, 14: 79-94, 2002.

Tyler LK, Stamatakis EA, Jones RW, Bright P, Acres K and MARSLEN-WILsON WD. Deficits for semantics and the irregular past tense: A causal relationship? Journal of Cognitive Neuroscience, 16: 1159-1172, 2004.

ULLMAN MT. The declarative/procedural model of lexicon and grammar. Journal of Psycholinguistic Research, 30: 37-69, 2001.

Ullman MT. Contributions of memory circuits to language: The declarative/procedural model. Cognition, 92: 231-270, 2004.

Ullman MT, Corkin S, Coppola M, Hickok G, Growdon J, Koroshetz W and PINKer S. A neural dissociation within language: Evidence that the mental dictionary is part of declarative memory, and that grammatical rules are processed by the procedural system. Journal of Cognitive Neuroscience, 9: 266-276, 1997

WUNDERLICH D. A minimalist model of inflectional morphology. In Wilder $\mathrm{C}(\mathrm{Ed})$, The Role of Economy Principles in Linguistic Theory. Berlin: Akademie-Verlag, 1996.

Martina Penke, Department of General Linguistics, Institut of Language and Information, Heinrich-Heine University Düsseldorf, D-40225 Düsseldorf, Germany. e-mail: penke@phil-fak.uni-duesseldorf.de 